\title{
Scientific Writing: A Blended Instructional Model
}

MaryAnn Clark, Seton Hall University, USA

Valerie Olson, Seton Hall University, USA

\begin{abstract}
Scientific writing is composed of a unique skill set and corresponding instructional strategies are critical to foster learning. In an age of technology, the blended instructional model provides the instrumental format for student mastery of the scientific writing competencies. In addition, the course management program affords opportunities for ongoing student-faculty communication, electronic access to the research literature and submission of student assignments, and student empowerment for self-directed learning. This has been a successful experience for students and faculty, and the ongoing collaboration has served as a catalyst to scholarship of scientific writing.
\end{abstract}

Keywords: educational strategies; curriculum development; doctoral education

\section{INTRODUCTION}

Q

cholarship is characterized by effective and efficient dissemination of research findings and scientific writing serves is the predominant avenue for researchers to contribute to the expanding professional knowledge base. Graduate student research skills and scientific writing are fostered in a variety of ways, and culminates in the development and writing of original research embodied in the doctoral dissertation, the capstone of doctoral studies. However, the lack of scholarly writing skills is common upon graduate students, and typically the instruction of the process and technical aspects of scholarly writing is not emphasized until the dissertation (Caffarella \& Barnett, 2000). Consequently, it is imperative that students achieve critical competencies of scientific writing throughout their academic tenure in order to successfully articulate research in writing (Collier \& Morgan, 2008). In the Department of Graduate Programs of Health Sciences, Seton Hall University, the traditional on-campus scientific writing course has been instrumental to achieve these goals. With the increased availability of technology and the changing needs of students, the scientific writing course evolved to a blended instructional model to transform graduate students into prolific and skilled communicators through the use of the written word.

\section{BLENDED MODEL}

The blended model of instruction for doctoral students was the logical result of ongoing program and course assessment of the research component of the curriculum. The model incorporates both on-ground and on-line teaching strategies designed to engage students both synchronously and asynchronously. The goal is to enhance a high level of student engagement and learning within a strategically planned educational environment. In addition, the organized teacher-student and student-student interaction fosters the ongoing learning dialogue, similar to Laurillard's Conversational Framework (Wong et al., 2010). Consequently, primary, secondary and tertiary course learning outcomes were identified and implemented.

Primary learning outcomes focused on the improvement and mastery of writing skills. These outcomes concentrated on syntax and format. Students were introduced to a variety of publication styles and the need to review guidelines from various peer reviewed journals to determine specific variations.

Information literacy is often viewed as a goal attained during undergraduate education. With students returning to graduate school perhaps many years removed from their previous college experiences, the world of 
information literacy has changed. Use of computers in educational strategies, although often assumed to be a skill in which all students are proficient, is often severely lacking with returning adult learners. To address this identified problem, secondary course outcomes were developed including mastery of an online teaching/learning platform (BlackBoard ${ }^{\mathrm{TM}}$ ), electronic database searching, use of plagiarism software, and blogs.

Tertiary outcomes were considered during course development. Instilling the motivation to become a lifelong learner takes on a new perspective when one considers the adult student returning to college. Professional development in time management, self-motivation and self- direction are skills adults manage in their daily lives, but may not coincide with their individual perspectives and experiences as college students.

\section{THE COURSE}

The selection of instructional strategies was aligned with the primary, secondary and tertiary course learning outcomes. The blended model scientific writing course was developed by two co-instructors and was initiated in the 2008 summer semester. On-going departmental curricular review revealed that the course should be required at the outset of the students' doctoral experience, which is also supported by the literature (Collier \& Morgan, 2008). Departmental review also recommended that the course move from an abbreviated summer session to a full semester (either fall or spring) to provide students with adequate time to develop the required skills. Additionally, it would be offered as a "tools" course that would provide students with basic information literacy skills that should prove beneficial for the remainder of their educational experience and beyond.

Three graduate credits were allocated and the course was classified as required for all matriculated students in the PhD program. Currently, the class meets on-ground in a computer enhanced environment on campus for approximately twenty percent of time, on-ground for fifteen percent in student led research presentations, with the remaining sixty percent of the structured instructional sessions provided online.

Students were required to submit blog entries to the professors on a weekly basis. All blog entries are available only to the individual student and the professor. This strategy provides individualized instruction and mentorship and, in most cases, takes the place of meetings that were previously scheduled during specific office hours. All written assignments are submitted online through the electronic educational platform and screened through its plagiarism software program prior to grading. Students had the opportunity to submit to the plagiarism checking program for practice feedback prior to uploading their final papers for instructor assessment, thus giving the student an opportunity to make personal adjustments prior to receiving a grade. Although available for instructor access, none of the "practice sessions" were reviewed by the instructor and they were not required, thus serving as a self-checking opportunity for the students. Once the written assignments were submitted for instructor evaluation, reports were provided on levels of plagiarism prior to grading. These reports were considered in the assignment's assessment and grading.

Weekly supplemental readings were provided on-line that augmented assigned portions of the course's required text. Strategically developed discussion board questions were posted every week that gave the opportunity for interaction with classmates, as well as faculty on directed topics. Participation in the discussion was required and included in the final grade for the course.

A series of writing assignments with clear expectations were required and strategically sequenced over the course of the semester to enhance learning and the provision of constructive feedback (Kleuver, 1997). Beginning assignments included electronic database searching to locate three related articles on the student's topic of choice. No overlapping authors or journals were permitted. Instruction in database searching was provided in one of the early on-ground class meetings by a university research librarian. All students were required to download the articles and then submit them for instructor review. Following the selection of the articles, the students were required to develop annotated bibliographies for each following a specific format that was provided through the supplemental readings. This process was repeated a second time giving the students six different articles and six accompanying annotated bibliographies. 
Using a peer-to-peer model in assessment and feedback was an important consideration in the scientific writing process (Kumar \& Stracke, 2007). Subsequently, students were assigned partners to whom they submitted their annotated bibliographies. Each peer was required to evaluate and provide feedback to his partner. This process was considered in the overall course grading.

Writing skills progressed through the development of an integrated paper, which was a compilation and interaction of the six articles that each student selected. Again, this assignment was evaluated by the instructor and was assigned to a classmate (different than the first) for peer review. Feedback was sent to the individual student from both the instructor and the peer reviewer. Revisions were made by the authors and the integrated paper was resubmitted to the instructor as the course's capstone requirement. Regular and constructive feedback on students' writing and progress also enhanced student satisfaction (Zhao et al., 2007).

The on-ground sessions were developed to assist the student with a smooth progression through the course and allow for face-to-face interactions among all participants. These sessions covered a variety of topics that were more easily presented in a live format and included: introductory material on navigation of the teaching/learning online platform; library database searching; use of an electronic database manager; participation and critique of student research presentation; and final course evaluation

\section{ASSESSMENT}

Assessment of student learning was accomplished utilizing several different strategies, with emphasis on the multidirectional dialogue among students and faculty (Birenbaum \& Amdur, 1999). Competency in working with the on-line educational platform was ongoing, as access to and use of course materials were expected at least weekly. Additionally, the platform provided the instructor with the opportunity to track the number of views of all the materials initiated by the students. Proficiency in database searching and quality of selection of peer reviewed publications on a similar topic was evaluated through submission of the articles to the instructor.

Student feedback consisted of positive statements regarding the individualized mentorship, both on-line and on-ground, as well as the independent learning component of the blended model. The course assessment addressed student, faculty, and program outcomes individually and in relationship to the others. Comments provided by the students included: "Now that I have taken this class, I have a much better idea on how to write a paper..." "This class should be the first class in the program. Last year was trying for me until (the instructor) showed the way." "Learning research and writing skills are absolutely essential for beginners in (graduate school). Many of us have been out of the academic world for 4-5 years and to begin with scientific writing will diminish fear." "I liked this online format as it gave everyone the opportunity to work at their own pace and on the own individual project."

\section{CONCLUSION}

Clearly, the outcomes of the incremental learning and the use of various active learning strategies were evident in the students' development and mastery of selected skills in scientific writing. Additional positive support consisted of the triangulation of students' ongoing input and final evaluations, samples of improved written work, and cumulative course assessments. The use of the blended instructional model was effective in the scientific writing course and warrants further research to ascertain its optimal use.

\section{AUTHOR INFORMATION}

Dr. Clark is professor of Health Sciences in the Department of Graduate Programs in Health Sciences at Seton Hall University. She received her EdD in Higher Education Administration and Management from University of Houston in 1983. Her current teaching responsibilities include scientific writing and research project design and methodology, as well as dissertation mentorship. Her current research interests include assessment of childhood obesity, teaching strategies, and higher education assessment and accreditation.

Dr. Olson serves as Associate Faculty at Seton Hall University, New Jersey. She earned her BS in Physical Education from Southern Connecticut University, MS in Exercise Science from University of Massachusetts, and a 
BS in Health Sciences with a certificate in Physical Therapy from the University of Florida. Dr. Olson earned her $\mathrm{PhD}$ in Health Sciences from Seton Hall University. For over 25 years, Dr. Olson has been involved in administration, teaching, service, and research in higher education. Current research emphases are noted in teaching and learning, use of technology in education, and movement science.

\section{REFERENCES}

1. Birenbaum, M. \& Amdur, L. (1999). Reflective active learning in a graduate course on assessment. Higher Education Research and Development, 18(2), 201-218.

2. Caffarella, R.S., \& Barnett, B. G. (2000) Teaching doctoral students to become scholarly writers: The importance of giving and receiving critiques. Studies in Higher Education, 25(1), 39-52.

3. Collier, P., \& Morgan, D. (2008, April). "Is that paper really due today?": differences in first-generation and traditional college students' understandings of faculty expectations. Higher Education, 55(4), 425-446.

4. Kleuver, R. (1997). Students' attitudes towards the responsibilities and barriers in doctoral study. New Directions for Higher Education, 99, 47-56.

5. Kumar, V., \& Stracke, E. (2007). An analysis of written feedback on a PhD thesis. Teaching in Higher Education, 12(4), 461-470.

6. Wong, G., Greenhalgh, T., Pawson, R. (2010). Internet-based medical education: a realist review of what works, for whom and in what circumstances. BMC Medical Education,10(12).

7. Zhao, C., Golde, C., \& McCormick, A. (2007). More than a signature: How advisor choice and advisor behaviour affect student satisfaction. Journal of Further and Higher Education, 31(3), 263-281. 